\title{
Ontogenetic Relationships Between Cranium and Mandible in Coyotes and Hyenas
}

\author{
Suzanne La Croix, ${ }^{1 *}$ Kay E. Holekamp, ${ }^{1}$ John A. Shivik, ${ }^{2}$ Barbara L. Lundrigan, ${ }^{1}$ \\ and Miriam Leah Zelditch ${ }^{3}$ \\ ${ }^{1}$ Department of Zoology, Michigan State University, East Lansing, Michigan \\ ${ }^{2}$ USDA Wildlife Services National Wildlife Research Center, Utah State University, Logan, Utah \\ ${ }^{3}$ Museum of Paleontology, University of Michigan, Ann Arbor, Michigan
}

ABSTRACT Developing animals must resolve the conflicting demands of survival and growth, ensuring that they can function as infants or juveniles while developing toward their adult form. In the case of the mammalian skull, the cranium and mandible must maintain functional integrity to meet the feeding needs of a juvenile even as the relationship between parts must change to meet the demands imposed on adults. We examine growth and development of the cranium and mandible, using a unique ontogenetic series of known-age coyotes (Canis latrans), analyzing ontogenetic changes in the shapes of each part, and the relationship between them, relative to key life-history events. Both cranial and mandibular development conform to general mammalian patterns, but each also exhibits temporally and spatially localized maturational transformations, yielding a complex relationship between growth and development of each part as well as complex patterns of synchronous growth and asynchronous development between parts. One major difference between cranium and mandible is that the cranium changes dramatically in both size and shape over ontogeny, whereas the mandible undergoes only modest shape change. Cranium and mandible are synchronous in growth, reaching adult size at the same life-history stage; growth and development are synchronous for the cranium but not for the mandible. This synchrony of growth between cranium and mandible, and asynchrony of mandibular development, is also characteristic of a highly specialized carnivore, the spotted hyena (Crocuta crocuta), but coyotes have a much less protracted development, being handicapped relative to adults for a much shorter time. Morphological development does not predict life-history events in these two carnivores, which is contrary to what has been reported for two rodent species. The changes seen in skull shape in successive life-history stages suggest that adult functional demands cannot be satisfied by the morphology characterizing earlier life-history stages. J. Morphol. 272:662-674, 2011. ๑ 2011 Wiley-Liss, Inc.

KEY WORDS: ontogeny; skull morphology; carnivore; geometric morphometrics; life history; coyote; hyena

\section{INTRODUCTION}

The coordination between form and function is of particular interest during ontogeny because each life-history stage represents a temporal ecological niche, and animals must be adapted to that niche to survive to the next stage. Moreover, because developing organisms continually change their morphologies, they must reconcile the conflict between demands of survival within the current life-history stage with those of maturation as they negotiate the transitions through succeeding stages (Wainwright and Reilly, 1994; Monteiro et al., 1999; Herrel and Gibb, 2006). The ontogenetic relationship between cranium and mandible is of special interest because these two parts must function in concert while both change along steep growth trajectories. Not only does each part exhibit its own ontogenetic change but also their ontogenetic coordination is necessary to ensure continuous functionality. Understanding the ontogenetic changes in mandibular shape and their integration with the cranium is basic to understanding the function of the developing feeding apparatus especially the way in which young mammals negotiate the challenges posed by competition with adults.

Young mammals do not compete directly with adults for food early in postnatal development but they must often be able to do so after weaning. During their initial postnatal development, the skull undergoes tremendous changes in both size and shape (Fig. 1), and the cranium and mandible must function to satisfy the feeding needs of a

\footnotetext{
Additional Supporting Information may be found in the online version of this article.

Contract grant sponsors: Graduate School, the College of Natural Sciences and the Department of Zoology at Michigan State University; Contract grant sponsor: NSF; Contract grant numbers: I0B0618022, I0S0819437. *Correspondence to: Suzanne La Croix, Department of Zoology,
203 Natural Science Building, Michigan State University, East
Lansing, MI 48824. E-mail: lacroixs@msu.edu.
}

Received 13 July 2010; Revised 2 November 2010; Accepted 12 November 2010

Published online 11 April 2011 in

Wiley Online Library (wileyonlinelibrary.com)

DOI: $10.1002 /$ jmor.10934 


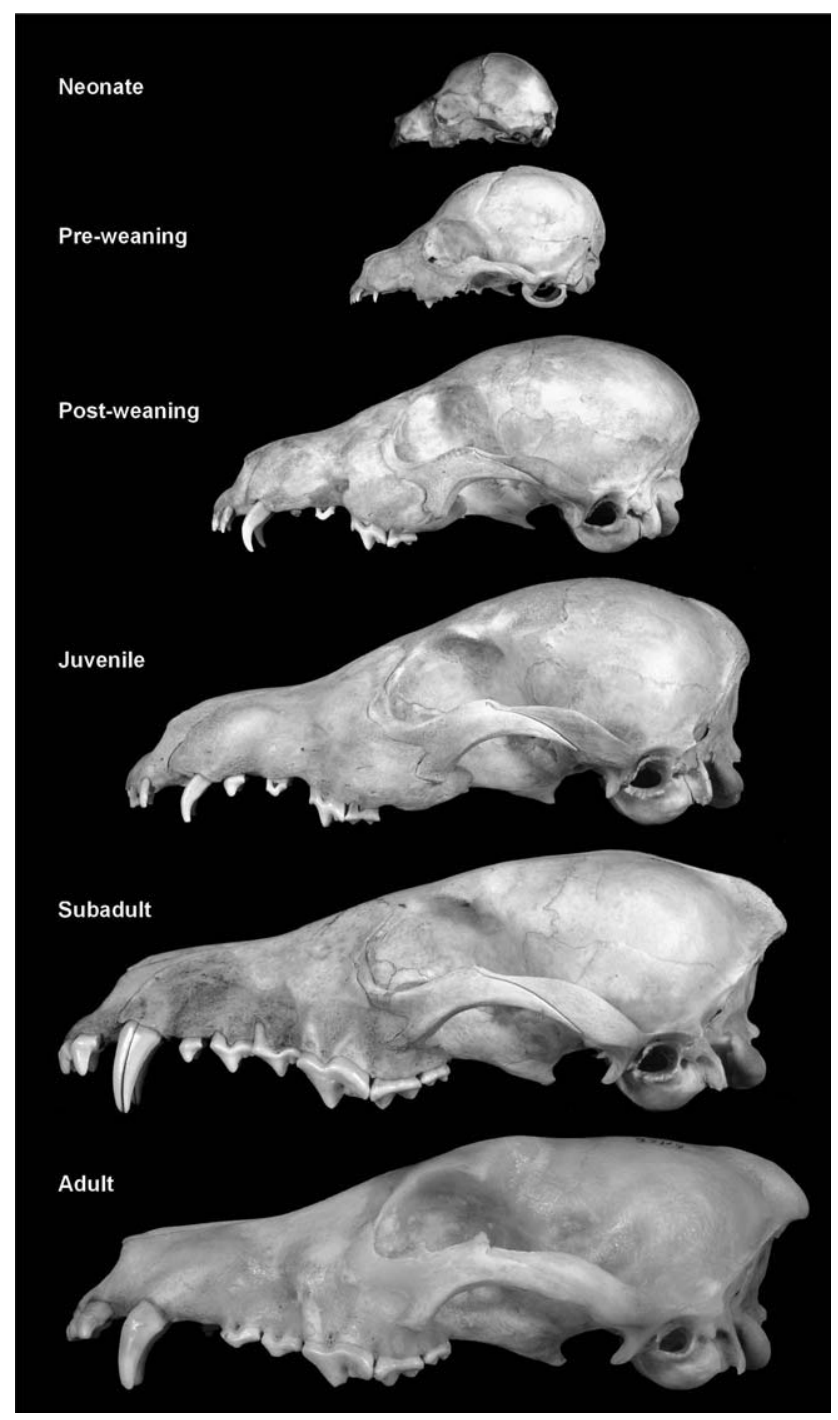

Fig. 1. Changes in cranium size and shape are visually dramatic among coyotes in successive life history stages.

juvenile, which are not necessarily those of an adult. To investigate the ontogeny of the feeding apparatus, and the relationships among its components, a complete description is needed of both the developing cranium and mandible. Although there are numerous descriptions of the developing cranium, there are presently few detailed descriptions of the ontogeny of mandibular shape (Cardini and Tongiorgi, 2003; Boughner and Dean, 2008; Christiansen, 2008), much less of the two parts taken together (but see, Cardini and O'Higgins, 2005).

The cranial shape maturity predicts the timing of life-history, and developmental milestones have already been shown for two rodent species with disparate life-history strategies (Mus and Sigmodon spp., Zelditch et al., 2003). It is not clear whether cranial shape maturity is equally predictive in other mammalian orders because only one comparable study has been published (Order Carnivora, Tanner et al., 2010); patterns of growth and development may be as myriad as life-history strategies. Further, it is not known whether mandibular shape maturity can likewise predict lifehistory scheduling. Understanding the relationship between development of the feeding apparatus (the skull) and life-history schedules is important because it has obvious implications for fitness.

We capitalized on a unique opportunity to assemble a large ontogenetic series of known-age skulls of coyotes (Canis latrans) and provide detailed descriptions of the ontogenetic allometry of a nondomesticated canid utilizing shape-based geometric morphometrics. Our investigation considers the ontogeny of the cranium and mandible concurrently, which is vital to understanding their temporal relationship and integration across postnatal development. These descriptive data serve as a useful contrast with those obtained from more specialized carnivores (e.g., spotted hyena, Tanner et al., 2010), a baseline for studies of variation within the genus Canis (e.g., Wayne, 1986; Kieser and Groeneveld, 1992), and a groundwork for future studies of the ontogeny of coyote feeding performance (La Croix et al., unpublished data).

Here, we first describe the ontogenetic trajectories for age-related change in shape of the coyote cranium and mandible across the entire lifespan. Next, we investigate whether these ontogenetic trajectories are simple or composed of multiphase stages and describe any temporally restricted shape change. Nonlinear growth models are fitted to our data to describe cranial and mandibular growth (i.e., changes in size over ontogeny) and development (i.e., changes in shape over ontogeny), examine sexual dimorphism, and assess growth and development within the context of the coyote's life history. We then describe the ontogenetic patterns and temporal coincidence of skull growth and development including their synchrony, or lack thereof, and implications for functionality of the feeding apparatus. Finally, we contrast these patterns of development in coyotes with those in a highly specialized carnivore, the spotted hyena (Crocuta crocuta), to uncover more generalized patterns of skull development and examine their relationship to life-history events.

\section{MATERIAL AND METHODS Coyote Life-History Stages}

The annual cycle of coyote life-history events begins with mating during January, February, and March (Bekoff, 1977). Following a 63-day gestation, pups are born beginning in March (Bekoff, 1977). Weaning of pups begins by four weeks of age and is usually completed by six weeks of age (Knowlton, personal communication; Snow, 1967; 5-7 weeks in Bekoff, 1977). The onset of deciduous tooth replacement occurs by 12 weeks of age, and eruption of the adult dentition is complete by 26 weeks of age (Bekoff, 1977; SLC, personal observation). Pups are 
TABLE 1. Life history stages of Canis latrans and the corresponding developmental milestones and ages in weeks. Sample sizes are given for skulls photographed for analyses in ventral cranium (V), lateral cranium (L), and mandible (M) views

\begin{tabular}{|c|c|c|c|c|c|}
\hline \multirow{2}{*}{$\begin{array}{l}\text { Life history } \\
\text { stage }\end{array}$} & \multirow[b]{2}{*}{ Developmental milestones } & \multirow[b]{2}{*}{ Age (weeks) } & \multicolumn{3}{|c|}{ Sample size } \\
\hline & & & $V$ & $L$ & $M$ \\
\hline Preweaning & Birth to weaning & 0.1 to 6 & 34 & 33 & 25 \\
\hline Postweaning & Weaning to onset of deciduous tooth replacement & 6 to 12 & 30 & 30 & 26 \\
\hline Juvenile & Onset to complete tooth replacement and adult tooth eruption & 12 to 26 & 27 & 28 & 27 \\
\hline Subadult & Completion of tooth replacement and eruption to 1st breeding & 26 to 93 & 25 & 26 & 27 \\
\hline Adult & 1st breeding to death & 93 to 694 & 26 & 26 & 25 \\
\hline
\end{tabular}

initially provisioned by both parents, and during the summer, the juveniles develop greater independence and self-reliance (Harrison and Gilbert, 1985; Harrison et al., 1991). Subadults of either sex may emigrate in the fall of the year; first breeding in nonpersecuted populations typically occurs at 22 months of age although both sexes are physiologically capable of breeding at 10 months of age (Bekoff, 1977; Bekoff and Gese, 2003).

Here, we divide the coyote's life history into five stages (Table 1) based on documented life-history milestones. The preweaning stage lasts from birth until weaning, at six weeks of age (Bekoff, 1977). The postweaning stage lasts from weaning until the onset of deciduous tooth replacement, at $\sim 12$ weeks of age (Bekoff, 2001). The juvenile stage lasts from the onset of deciduous tooth replacement until eruption of adult dentition is complete, which occurs by 26 weeks of age (SLC, personal observation). The subadult stage starts with the complete eruption of adult dentition at 26 weeks of age and ends with first breeding, at $\sim 93$ weeks of age (Bekoff and Gese, 2003). The adult stage extends from first breeding to death, which may occur at 13 or more years.

Among canids, coyotes are usually categorized as omnivorous generalists, with young coyotes capitalizing on that portion of the adult diet that is most easily obtained or subdued (Clark, 1972; Bowen, 1978; Johnson, 1978; Andelt et al., 1987; Gese et al., 1996; Hidalgo-Mihart et al., 2001; Arjo et al., 2002; Hernandez et al., 2002). Following weaning, juvenile coyotes are initially provisioned by their parents; subsequently, they ingest mostly small mammals, vegetation, invertebrates, and birds, whereas adults consume larger mammals, fewer invertebrates, and few birds (Hawthorne, 1970). Fruit and insect ingestion by coyotes occurs most frequently in the summer, which corresponds temporally with a coyote pup's increasing independence (Young et al., 2006).

\section{Specimens}

An ontogenetic series of 187 coyote skulls (102 males and 85 females), all of known age, was used in this study; sample sizes are shown in Table 1 . Individuals ranged in age from 1 day to 13.3 years, including 79 specimens under the age of 6 months. All specimens were prepared by and catalogued into either the Michigan State University Museum collection or the United States Department of Agriculture/APHIS/Wildlife Services National Wildlife Research Center's Logan Field Station collection in Millville, UT (Supporting Information Appendix Table A.1.).

Specimens were collected incidentally from a captive colony of coyotes comprised of animals of wild-caught and colony parentage and maintained at the Logan Field Station between 1979 and 2006. Within the ontogenetic series, 179 specimens were captive born, including all specimens under the age of 1 year, whereas eight were wild born. All animals were captive reared, and although this study did not investigate whether the observed ontogenetic patterns are equivalent to those found in the wild, rearing conditions at the Logan Field Station were designed to be as natural as possible. All animals were maintained on a commercially produced wet food diet designed for fur bearing animals and containing chicken (beaks, feet, and feathers) and grain. USDA/APHIS/WS/NWRC IACUC approved the study protocol QA-1179.

Exact dates of death were known for all individuals, and exact dates of birth were known for all captive-born animals. For animals obtained from the wild as pups, dates of birth were estimated by the original collectors based on deciduous tooth eruption and den observations; those estimated dates of birth were used here. Collector and animal records for all specimens are maintained at the Logan Field Station.

\section{Ontogenetic Shape Change}

Ontogenetic changes in cranial and mandibular growth and development were analyzed by geometric morphometrics (Rohlf and Slice, 1990; Zelditch et al., 2004). Each cranium was photographed in ventral and lateral views. In ventral view, the skull was oriented with the palate parallel to the photographic plane, and in lateral view, the skull was oriented with the mid-sagittal plane parallel to the photographic plane. Mandibles were photographed in lateral view, oriented with the longest axis of the mandible parallel to the photographic plane; only mandibles with intact symphyses were photographed. To assess measurement error, an initial sample of 121 crania was photographed in ventral and lateral views at three different times by the same observer. Measurement error was determined to be negligible, accounting for only $1.2 \%$ of the variation in the sample. The remaining 66 specimens were thus photographed and digitized only once; mandibles were photographed and digitized only once. Twenty-seven landmarks visible on photographs of the ventral cranium provide the data for the analysis of shape in that view (Fig. 2a). Landmarks alone cannot fully capture the dorsal curve of the lateral cranium or the mandibular ramus, so these were analyzed using a combination of landmarks and semilandmarks. Semilandmarks, unlike landmarks, are not discrete anatomical loci that can be recognized as homologous points, and they contain less information than landmarks because their spacing along the curve is arbitrary. However, semilandmarks make it possible to study complex curving morphologies where landmarks are sparse. Fourteen landmarks and 32 semilandmarks were selected for the lateral cranium (Fig. 2b), and 11 landmarks and 75 semi-landmarks were selected for the mandible (Fig. 2c). Descriptions of these landmarks are contained in Supporting Information Appendix Table A.2. Landmarks and semilandmarks were digitized using tpsDig2.10 (Rohlf, 2005). For semilandmarks, the curve-tracing function was applied, and semilandmarks were evenly spaced along the curves using the "resample" function of the curvetracing tool.

Landmarks were superimposed using Generalized Procrustes Analysis to remove variation in scale, position, and orientation (Rohlf and Slice, 1990; Zelditch et al., 2004). Semilandmarks require a specialized superimposition method because their spacing is biologically arbitrary. Semilandmarks were superimposed to minimize the Procrustes distance from the mean shape; we use this criterion for sliding semilandmarks because the Procrustes distance is the metric underlying the general theory of shape. According to this method, the tangent to the curve at each semilandmark is estimated and then each semilandmark is slid toward the normal of its respective tangent, 

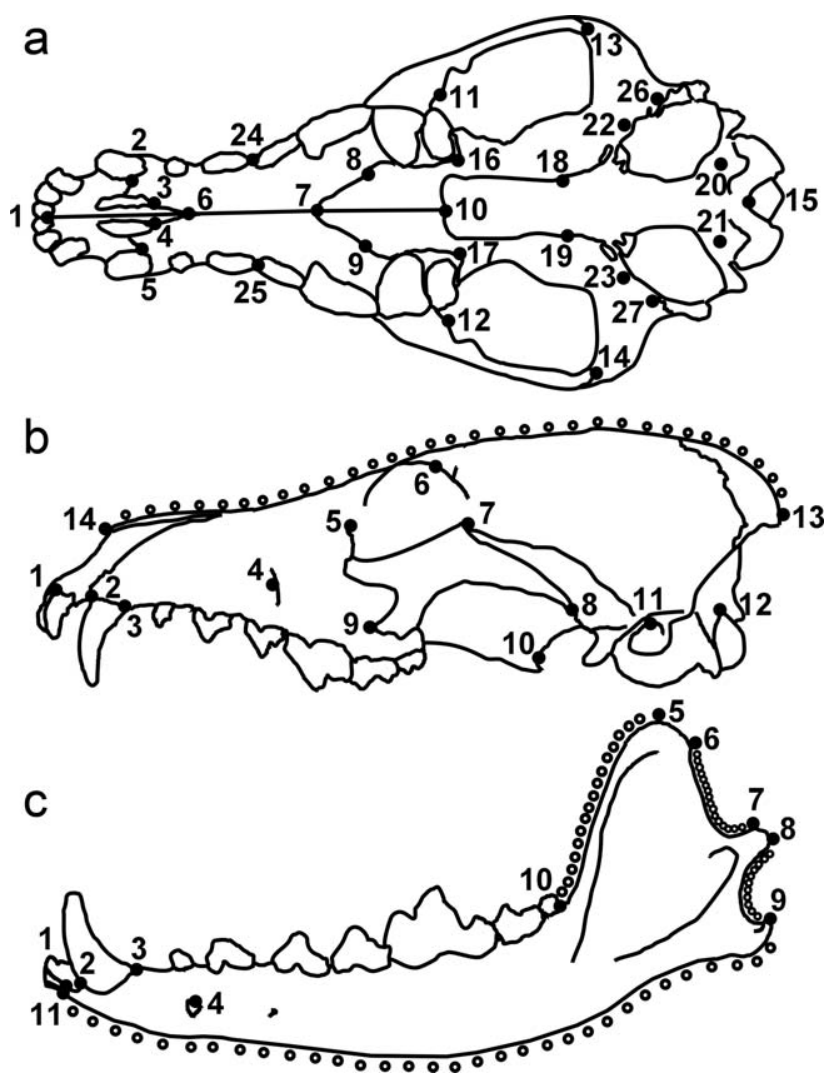

Fig. 2. Landmarks (numbered) and semilandmarks (o) shown on the cranium (a: ventral, b: lateral) and mandible (c) of an 18-month-old coyote, Canis latrans. Descriptions of each landmark and semilandmark are provided in Supporting Information Appendix Table A.2.

minimizing the overall difference from the reference (Sampson et al., 1996; Andresen et al., 2000; Bookstein et al., 2002). Following superimposition, semilandmarks can be used in conventional shape analyses provided that statistical tests take into account that they have only one degree of freedom. For the ventral cranium, bilaterally homologous landmarks were reflected and averaged after the Procrustes superimposition because bilaterally homologous landmarks are not independent of each other; to ease interpretation of the visual results, they are shown as whole skulls. To quantify skull size, we used centroid size, the square root of the summed squared distances from each landmark to the geometric center of the object. Superimposition of landmarks was done using CoordGen6h (Sheets, 2009); semilandmarks were superimposed in SemiLand (Sheets, 2003). Reflection and averaging of bilateral landmarks was done in Sage (Marquez, 2007).

To analyze ontogenetic change in shape across the entire lifespan and within single life-history stages, shape was regressed on age; age was log-transformed because most shape change occurs early in ontogeny. The relationship between shape and age was tested for statistical significance using a generalized Goodall's $F$ test (Sheets, 2003; Rohlf, 2007), which measures the ratio of explained to unexplained variation in units of Procrustes distance. Adult coyotes are known to be sexually dimorphic in size; adult females are up to $20 \%$ smaller than males (Bekoff, 1977; Bekoff and Gese, 2003). We assessed whether the ontogeny of shape is also sexually dimorphic using Mancova, with sex as the main factor and age as the covariate. Because sexual shape dimorphism was not statistically significant in any view, we pooled males and females in the analyses of shape. Results are depicted using the thin-plate spline function (Bookstein, 1991).

Using linear regression to analyze the whole of ontogeny presumes that the same shape changes occur over all ontogenetic phases. To test the hypothesis that ontogeny is more complex than that, we subdivided our sample into five life-history stages (Table 1), and compared the ontogenetic trajectories of successive stages (so long as statistically significant age-related shape change was present within both single stages). Comparisons were done by measuring the angle between the vectors of ontogenetic change; should both point in the same direction, the angle between them is $0^{\circ}$. The statistical analysis tested the null hypothesis that the angle between the vectors was no greater than expected by chance. That was done by comparing the angle between successive life-history stages to the range of angles that could be obtained by resampling with replacement (400 times), as this is a bootstrap procedure, within a single stage. Should the angle between vectors exceed the $95 \%$ confidence intervals for both stages, the difference was judged statistically significant; such a difference does not imply that ontogeny changed direction at the boundary between stages. Regression was done in Regress6 (Sheets, 2003); comparisons between vectors were done in VecCompare (Sheets, 2003).

\section{Rates and Timing of Growth and Maturity}

To determine the age at which skull growth and development attained adult values, we used a series of nonlinear growth models to find the one that best fit the data for size and shape. Eight models, Chapman-Richards, Logistic, Monomolecular, Gompertz, German Gompertz, Von Bertalanffy, Quadratic, and Linear were fitted to the skull size and shape data and assessed for their relative goodness-of-fit using Aikaike Information Criterion (AIC; following Zelditch et al., 2003); the model with the lowest AIC value was judged to be the best so long as the residuals were not serially autocorrelated. Several models were excluded because they induced autocorrelations among residuals in one or more of the analyses (Supporting Information Appendix A.3. and A.4.). Of those that remained, several fit equally well. We chose the logistic model (following Gaillard et al., 1997) because this model not only fit the data well in all views, but it was the only model that did not induce autocorrelations among residuals in any of the analyses. This model was the basis for estimating rates and timing of growth and development:

$$
x(t)=A /\left\{1+e^{k(T o-t)}\right\}
$$

where $x(t)$ is the measurement of interest at time $t, A$ is the asymptotic maturity, $k$ is the rate of growth (rate of approach to asymptotic value), and $T_{0}$ is the age at the curve inflexion point (where growth has attained 50\% of asymptotic value; Gaillard et al., 1997; Zelditch et al., 2003). We report age at maturity as the estimated age at which the measurement of interest reaches $95 \%$ of asymptotic (adult) value. Data for individuals above the 95\% breakpoint were subsequently regressed on age to ensure that age had no further significant impact on the measurement of interest. Evaluation of growth models and estimation of parameters were performed using GrowChoice (Sheets, 2003).

To analyze rates and timing of growth, we used centroid size as our measure of size; analyses of rates and timing of development were done using the Procrustes distance between a particular specimen and the average for the youngest specimens (Zelditch et al., 2003). We used this measure because it does not require that species (or ontogenetic stages) have the identical trajectory for shape, unlike a more conventional procedure which compares rates and timings along a single ontogenetic trajectory (e.g., Alberch et al., 1979), nor does it divide the inherently multidimensional data of shape into a collection of one-dimensional parameters analyzed one at a time (e.g., McKinney and McNamara, 1991). Instead, the rate of shape change is estimated by the distance traveled along a speciesspecific shape trajectory relative to time (Gould, 1977; Zelditch 

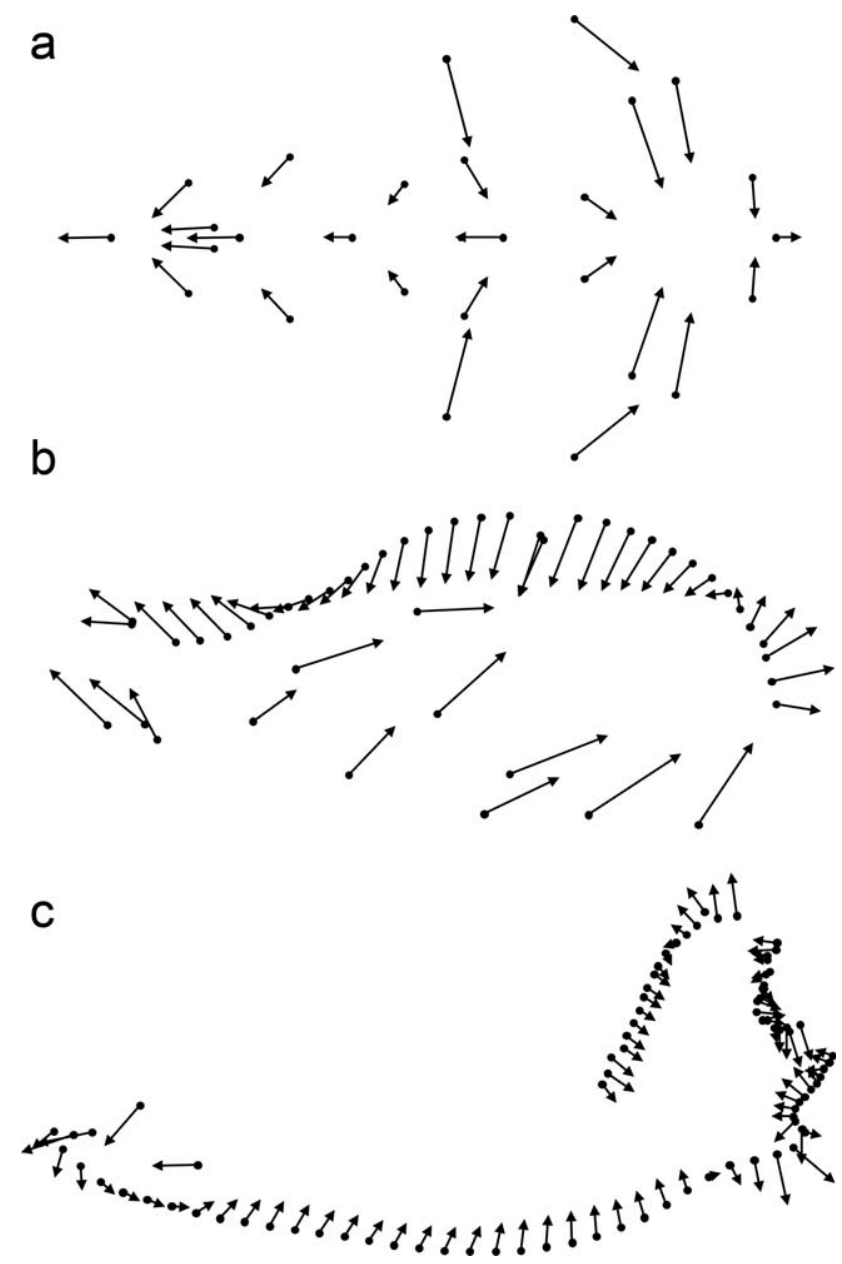

Fig. 3. Ontogenetic changes from a linear regression of shape on $\log$ (age) for the cranium (a: ventral, b: lateral) and mandible (c). Vectors on landmarks and semilandmarks show the direction and magnitude of change from the youngest to the oldest specimens after centroid size is scaled to the same size for each specimen.

et al., 2003; Tanner et al., 2010). A large Procrustes distance for a particular individual could mean that the individual is oddly shaped rather than mature, but we found no major outliers in our sample.

\section{RESULTS \\ Changes in Shape Across the Entire Life Span}

Statistically significant and visually dramatic ontogenetic changes in skull shape occur between 1 day and 13 years of age in all three views (Fig. 3). For all views, the null hypothesis of isometric growth can be rejected $(P<0.01)$. In ventral view, the dominant feature of shape change is the relative narrowing of the skull along the anteroposterior axis and lengthening of the rostrum (Fig. 3a). In lateral view, the cranial profile becomes less rounded, and the nuchal and occipital crests expand posterodorsally (Fig. 3b). The dominant features of mandible ontogeny are the relative expansion of the angular process and the marked anterodorsal reorientation of the coronoid process, resulting in a taller and more vertically oriented process in adults than neonates (Fig. 3c).

\section{Changes in Shape Within Life-History Stages}

Shape changes substantially throughout preweaning, postweaning, and juvenile stages for both cranial views; the null hypothesis of isometry can be rejected for those stages $(P<0.01)$. Isometry can also be rejected for the adult lateral view $(P=$ $0.011)$, but not for the adult ventral view $(P=$ $0.060)$ or the subadult cranial views $(P>0.05)$. For the mandible, age-related changes in shape are statistically significant in all but the adult life-history stage $(P<0.001)$. Comparisons between successive stages that exhibit statistically significant changes in shape reveal the complexity of ontogeny (Table 2). In all cases, the differences between stages are statistically significant and in some the angles are exceptionally large, especially in the case of the mandible, where the angles for pre- vs. postweaning, and juvenile vs. subadult, exceed $90^{\circ}$. It is clear from this that the dominant features of a complete ontogeny (as described above) cannot capture the ontogenetic dynamics of shape; we,

TABLE 2. Comparisons between ontogenetic trajectories of successive life history stages of Canis latrans for the ventral cranium, lateral cranium, and mandible views

\begin{tabular}{llccr}
\hline & \multirow{2}{*}{$\begin{array}{c}\text { Life history } \\
\text { stages compared }\end{array}$} & \multicolumn{2}{c}{ Age-related change in shape } \\
\cline { 2 - 5 } Skull view & Pre- vs. postweaning & $\mathbf{3 4 . 6}$ & Younger $\left(^{\circ}\right)$ \\
\hline Ventral & Postweaning vs. juvenile & $\mathbf{4 0 . 4}$ & 15.5 & Older $\left(^{\circ}\right)$ \\
Lateral & Pre- vs. postweaning & $\mathbf{4 6 . 7}$ & 26.6 & 20.9 \\
& Postweaning vs. juvenile & $\mathbf{2 6 . 3}$ & 20.3 & 14.9 \\
Mandible & Pre- vs. postweaning & $\mathbf{1 1 0 . 7}$ & 57.9 & 12.1 \\
& Postweaning vs. juvenile & $\mathbf{7 3 . 9}$ & 52.8 & 46.7 \\
& Juvenile vs. subadult & $\mathbf{9 7 . 1}$ & 45.3 & 53.7 \\
\hline
\end{tabular}

Comparisons were made between successive life history stages only in cases where both single stages exhibited significant agerelated change in shape. Ontogenetic trajectories of two successive stages were determined to differ significantly when the angle between the vectors of the two stages exceeded that obtained by resampling (400 times) within each stage (younger and older). If the observed angle between stages exceeded the $95 \%$ confidence interval of the two within-stage ranges, the difference was judged to be statistically significant, here indicated in bold font. 
therefore, describe the changes occurring within each stage.

During the preweaning stage (Figs $4 \mathrm{a}$ and 5a), nearly half of the variance in cranial shape is related to age (ventral view: $46.6 \%$, lateral view: 46.1\%). In this first stage, the cranium changes shape dramatically as the initially bulbous neonate skull undergoes a tremendous elongation of rostrum and palate, and the basicranium narrows relative to its length and diminishes in relative height. Further, the frontal and parietal bones align dorsally, creating a continuous dorsal curve, visible in the lateral view of the cranium. During the subsequent postweaning stage (Figs. $4 \mathrm{~b}$ and $5 b$ ), when feeding is accomplished with deciduous teeth, shape continues to change, but age accounts for a much lower proportion of the variance for ventral $(30.1 \%)$ than for lateral view (51.9\%). Rostral elongation continues, as does relative narrowing of the basicranium and flattening of the brain case, all of which further reduce the infant skull's bulbosity. Specific to the postweaning stage, the basicranium lengthens relative to skull length as evidenced by the posterior displacement of the landmarks for the jugular foramen and the posterior point of the foramen magnum. In the next interval, the juvenile stage (Figs. $4 \mathrm{c}$ and $5 \mathrm{c}$ ), the deciduous teeth are replaced by adult dentition. The proportion of ventral cranial shape accounted for by age here $(29.1 \%)$ is similar to that seen in the previous stage, but a greater proportion of the variance is accounted for by age in lateral view $(63 \%)$. During this stage, the general pattern of cranial elongation and dorso-ventral flattening continues, but now there is also expansion of the zygomatic arches (evident from the posterolateral displacement of the landmark at the jugal/squamosal suture), as well as enlargement of the sagittal crest, which lengthens and broadens, creating an increased area for origin of the temporal muscles. No statistically significant changes in cranial shape were detected during the subadult stage. However, in the adult stage (Figs. 4e and $5 e)$, cranial shape in the lateral view changed significantly, with age accounting for $9.5 \%$ of the variance while cranial shape in the ventral view was nearly significant $(P=0.060)$. Over this interval, shape change is mostly subtle except for a distinct widening of the zygomatic arches.

Age consistently explains little of the variance in mandibular shape $(9.4 \%, 10.8 \%, 16.3 \%$, and $11.8 \%$ for preweaning, postweaning, juvenile, and subadult, respectively). During the preweaning stage (Fig. 5f), the anterior portion of the mandible body elongates and deepens and the vertical ramus dramatically broadens. In the subsequent, postweaning stage (Fig. 5g), the mandible body and ramus (anterior to the condyloid process) broaden and deepen, and the condyloid process expands posteriorly. During the next juvenile stage (Fig. 5h), the a

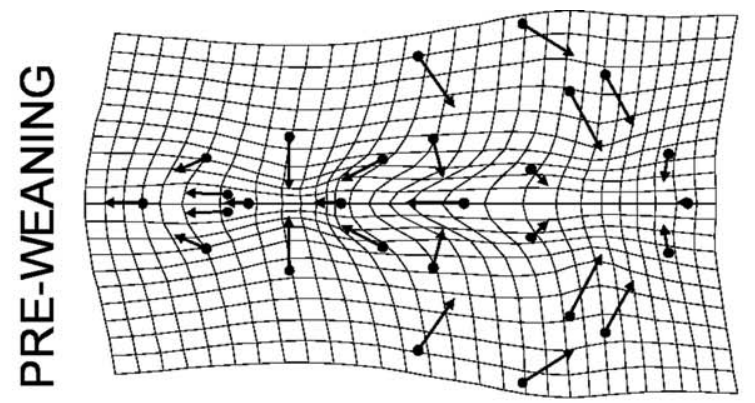

b

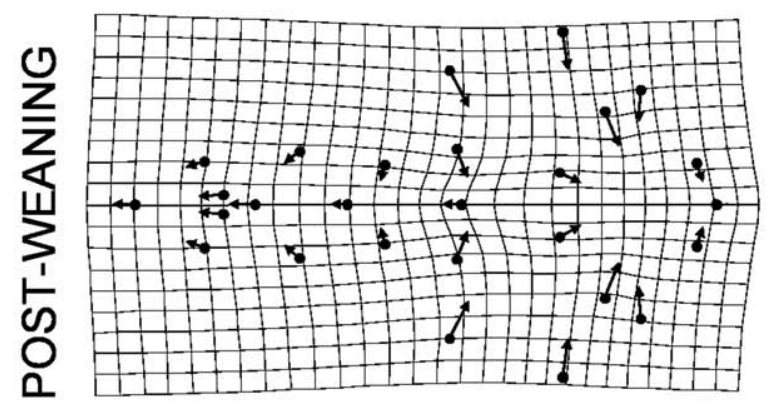

C

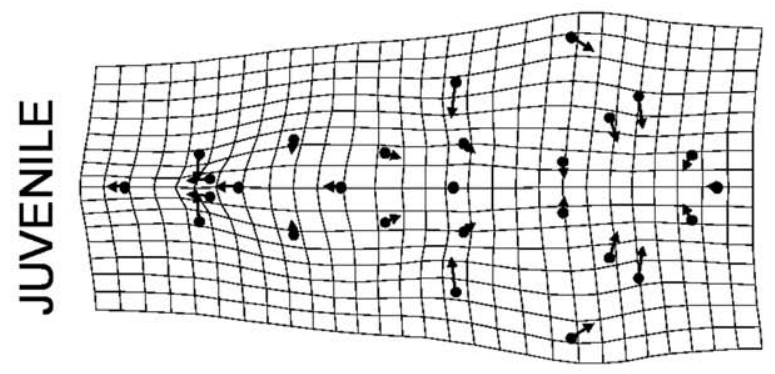

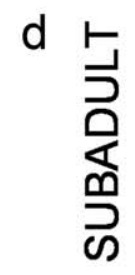

e

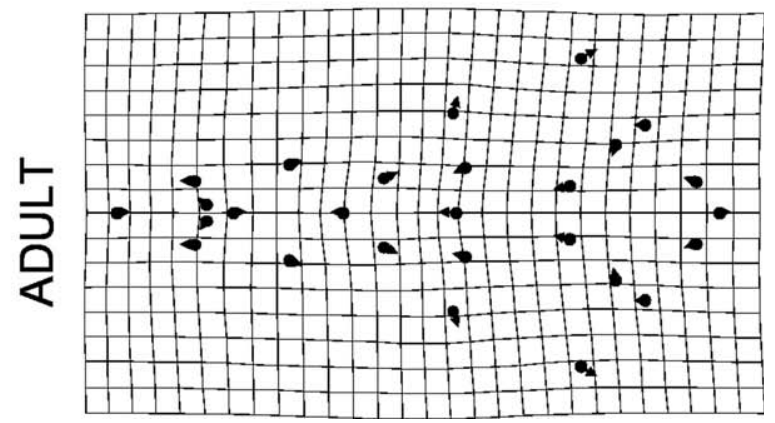

Fig. 4. Ventral view of the cranium showing the linear regression of shape on $\log$ (age) for each life history stage. Vectors show the direction and magnitude of change from the youngest to the oldest specimens in that life history stage after centroid size is scaled to the same size for each specimen. No statistically significant change occurred during the subadult period, so this stage is not shown. 
a

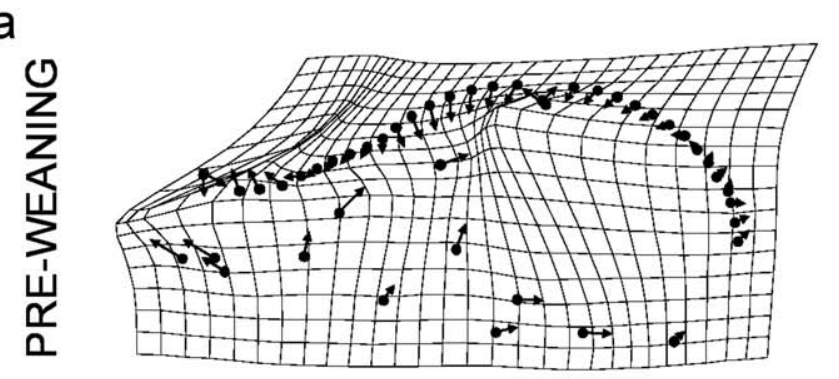

b

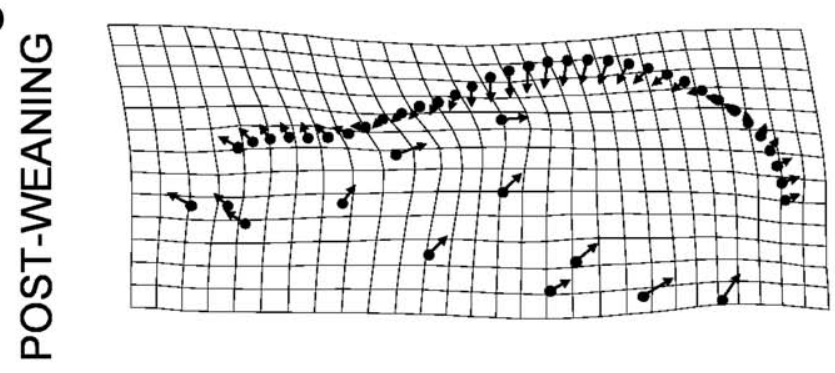

C

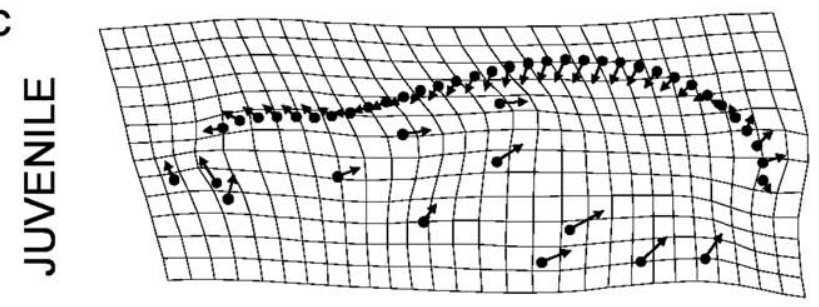

d

के

e

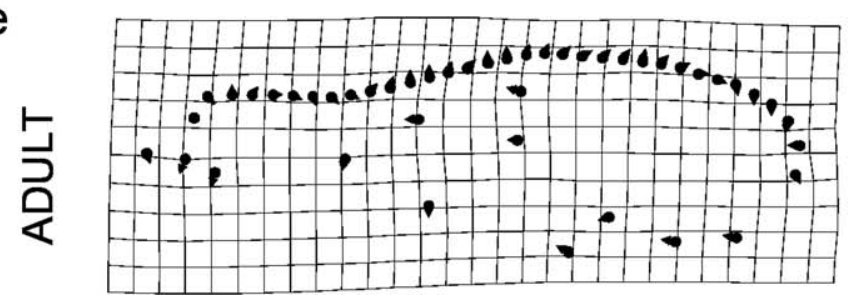

$f$

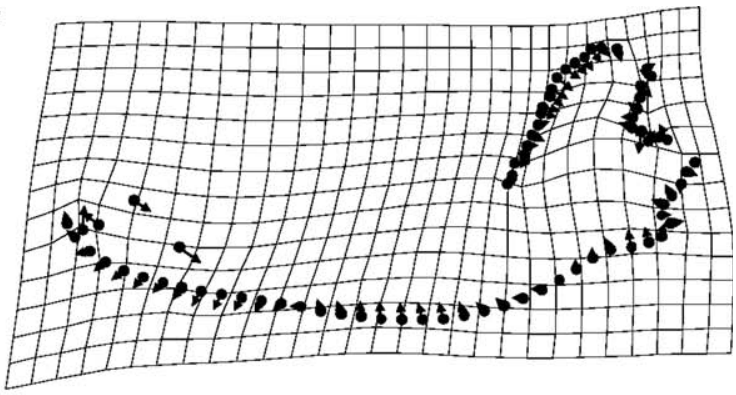

9

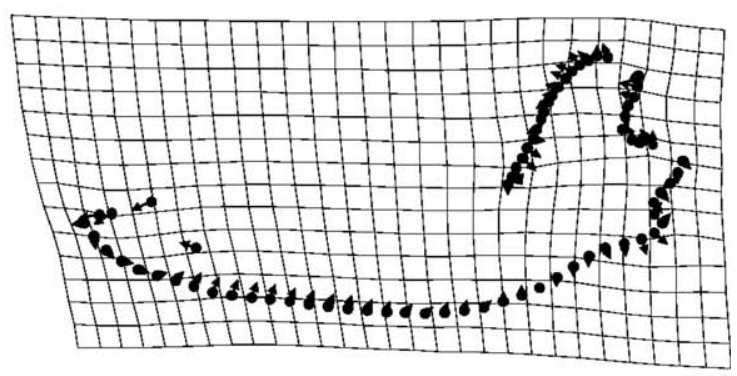

g

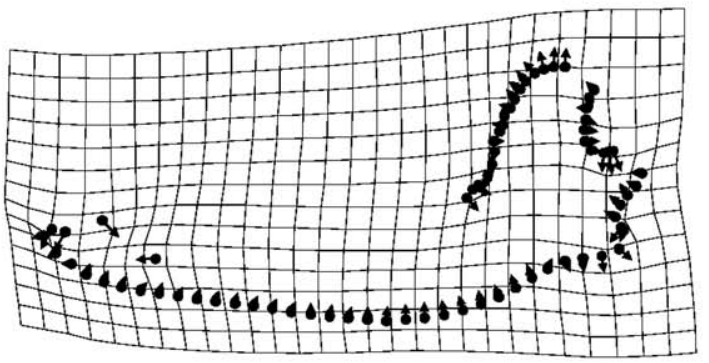

i

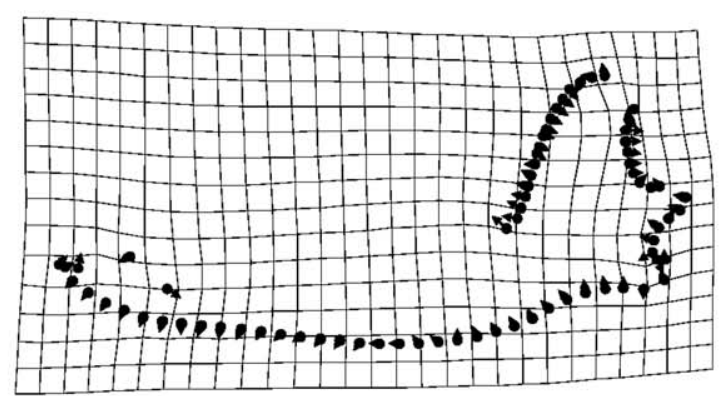

Fig. 5. Lateral cranium (a-e) and mandible $(\mathbf{f}-\mathbf{i})$ views of the linear regression of shape on $\log ($ age $)$ for each life history stage. Vectors and notation are as in Fig. 4.

coronoid process lengthens and broadens, whereas the vertical ramus elongates, becoming more perpendicular in orientation relative to the base of the ramus. During the subadult stage (Fig. 5i), there is an overall flattening and reduction in ventral curvature along the body of the ramus and ongoing growth at the extremes of the coronoid and condyloid processes. And as noted above, no 
TABLE 3. Best-fitting models for the measures of size (centroid size) and shape (Procrustes distance) maturity

\begin{tabular}{|c|c|c|c|c|c|c|c|}
\hline & \multirow{2}{*}{$\begin{array}{c}\text { Best-Fit } \\
\text { model }\end{array}$} & \multicolumn{3}{|c|}{ Female } & \multicolumn{3}{|c|}{ Male } \\
\hline & & AIC weight & $\mathrm{AC}$ & $\%$ Var & AIC weight & $\mathrm{AC}$ & $\% \operatorname{Var}$ \\
\hline \multicolumn{8}{|l|}{ Size } \\
\hline Ventral cranium & Logistic & 0.2186 & ns & 0.986 & 0.2307 & ns & 0.989 \\
\hline Lateral cranium & Logistic & 0.1943 & ns & 0.969 & 0.1942 & $\mathrm{~ns}$ & 0.978 \\
\hline Lateral mandible & Logistic & 0.2197 & $\mathrm{~ns}$ & 0.985 & 0.2363 & $\mathrm{~ns}$ & 0.989 \\
\hline \multicolumn{8}{|l|}{ Shape } \\
\hline Ventral cranium & Logistic & 0.2208 & ns & 0.974 & 0.2132 & $\mathrm{~ns}$ & 0.973 \\
\hline Lateral cranium & Logistic & 0.2172 & ns & 0.947 & 0.2379 & $\mathrm{~ns}$ & 0.960 \\
\hline Lateral mandible & Logistic & 0.1475 & ns & 0.750 & 0.1446 & ns & 0.690 \\
\hline
\end{tabular}

The AIC weight evaluates relative goodness-of-fit by balancing the distance between model and data by degrees of freedom. AC refers to serial autocorrelation among residuals of the model ("ns" indicates there was no statistically significant serial autocorrelation).

statistically significant changes in shape are detected during the adult stage for the mandible.

\section{Rates and Timing of Growth and Maturity}

The best-fitting model for both growth and development of the cranium and mandible is logistic growth (Table 3; see also, Supporting Information Appendix Tables A.3. and A.4.). Asymptotic adult size $(A)$ differs significantly between male and female coyotes (Table 4), so each sex was analyzed separately when estimating the age at which size and shape reached adult maturity (95\% of the asymptotic values). Among males, for both ventral and lateral views of the cranium, adult size is reached at 22.5 weeks, and for the mandible at 23 weeks. Females reach adult size within one week of males for all views of the skull (22 weeks). The age at which shape reaches adult maturity is not as consistent among views (Table 5). For the ventral skull, adult shape is reached at 17.2 weeks in males and 18 weeks in females, but the lateral skull takes three to four weeks longer, maturing by 21 weeks in both sexes. The mandible takes even longer, reaching adult shape at 28.2 weeks in both sexes.

Placed in the context of milestones regularly recorded in mammalian life-history studies, the cranium and mandible follow similar growth patterns (Table 6, Fig. 6a). Degree of maturation is similar at birth, and all views attain over half of their adult size by weaning (ventral view, $55 \%$ for males, $56 \%$ for females; lateral view, $60 \%$ for both sexes; mandible, $51 \%$ for males, $52 \%$ for females). By the onset of tooth replacement at 12 weeks, all have attained $\sim 80 \%$ of the adult size (ventral view, $77 \%$ for males, $78 \%$ for females; lateral view, $79 \%$ for males, $80 \%$ for females; mandible, $74 \%$ for males, $76 \%$ for females). The crania and mandibles reach maturity up to three weeks before the adult dentition completes eruption at 26 weeks (Fig. 7).

In striking contrast to their synchronous patterns of growth, cranial and mandibular shape show very disparate ontogenetic patterns. At birth, cranial shape is conspicuously immature, whereas mandibular shape is remarkably mature (Table 6, Fig. 6b). Over the first two life-history stages (preweaning and postweaning), cranial shape changes rapidly, such that, by the onset of tooth replacement, the cranium has progressed roughly $80 \%$ of the way to its mature shape for features visible in ventral view (83\% for males; $80 \%$ for females) and $65 \%$ for features visible in lateral view $(67 \%$ for males; $65 \%$ for females). Mandibular shape changes much more gradually, and although maturity at the onset of tooth replacement falls between the two cranial views (75\% for both sexes), the mandible does not reach adult shape until several weeks after the cranium; indeed, maturity of the mandible is not attained until two weeks after the adult dentition is in place (Fig. 7).

\section{DISCUSSION}

At birth, the coyote cranium is small and immature; both size and shape change dramatically over ontogeny. The coyote mandible, like the cranium, is also small at birth. However, unlike the cranium, the shape of the mandible is not immature at birth, and it changes only modestly in shape over ontogeny. In its cranial development, the coyote skull follows the general mammalian pattern (Moore, 1981): bulbous at birth with subsequent elongation of the cranium relative to its width, flattening of the lateral profile, and broadening of the zygomatic arches. The ontogeny of the mandible also follows a general mammalian pattern: an elongation of the horizontal body relative to its height, vertical reorientation and broadening of the upright ramus and coronoid process, and augmentation of the condyloid and angular processes. But the ontogenies of both parts are more complex than suggested by these general patterns; for each part there are features that change during only a specific phase of ontogeny. For example, the basicranium and nuchal crest are displaced posteriorly between weaning and the onset of deciduous tooth replacement, whereas the zygomatic arches 

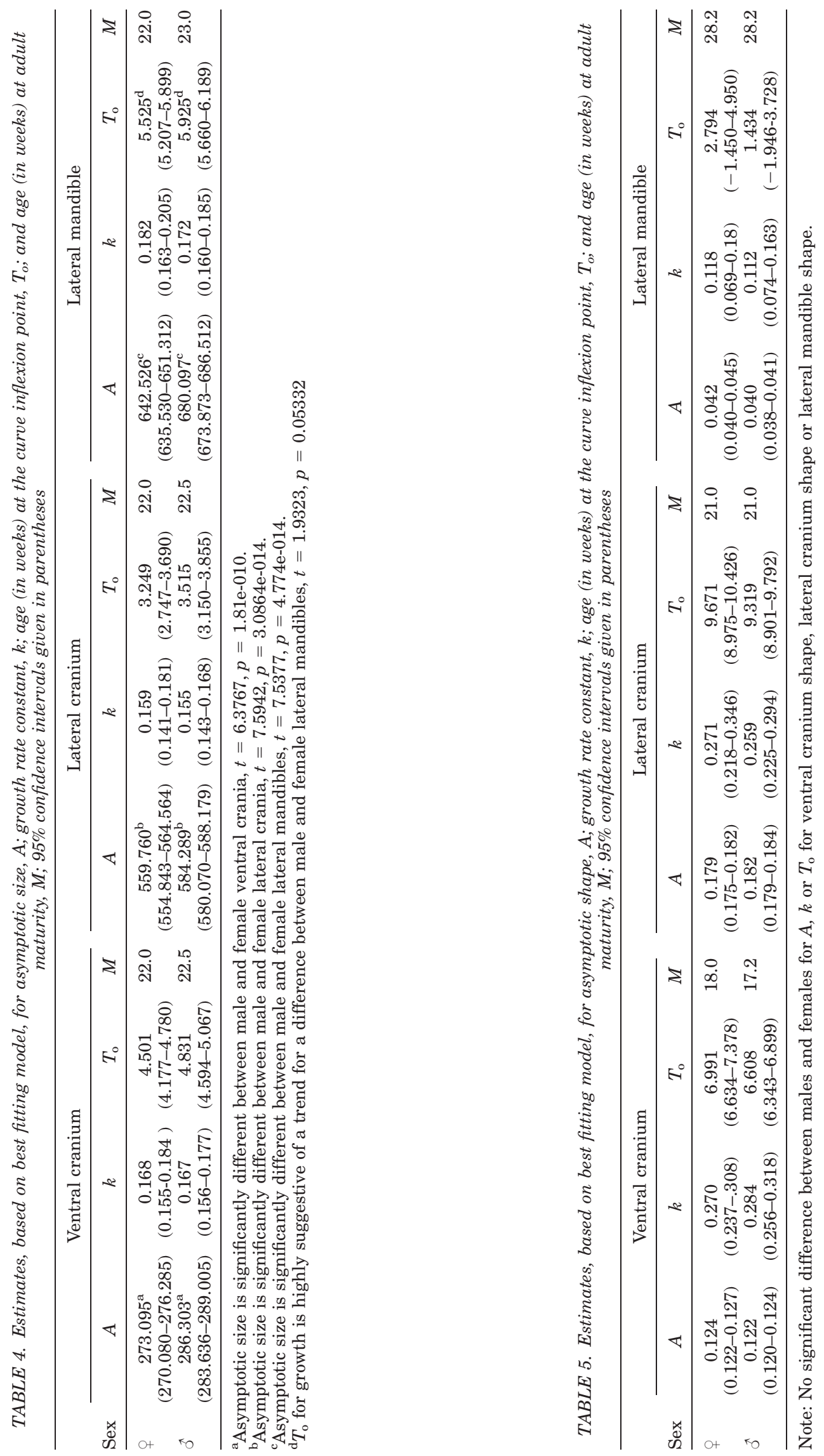
TABLE 6. Relative maturity of size (CS/A) and relative maturity of shape (PD/A) at post-natal ages, based on parameters of the logistic model

\begin{tabular}{|c|c|c|c|c|c|c|c|c|c|c|c|c|}
\hline \multirow{3}{*}{$\frac{\text { Age }}{\text { (Weeks) }}$} & \multicolumn{4}{|c|}{ Ventral cranium } & \multicolumn{4}{|c|}{ Lateral cranium } & \multicolumn{4}{|c|}{ Lateral mandible } \\
\hline & \multicolumn{2}{|c|}{ Female } & \multicolumn{2}{|c|}{ Male } & \multicolumn{2}{|c|}{ Female } & \multicolumn{2}{|c|}{ Male } & \multicolumn{2}{|c|}{ Female } & \multicolumn{2}{|c|}{ Male } \\
\hline & $\mathrm{CS} / \mathrm{A}$ & $\mathrm{PD} / \mathrm{A}$ & $\mathrm{CS} / \mathrm{A}$ & PD/A & CS/A & PD/A & $\mathrm{CS} / \mathrm{A}$ & $\mathrm{PD} / \mathrm{A}$ & $\mathrm{CS} / \mathrm{A}$ & $\mathrm{PD} / \mathrm{A}$ & $\mathrm{CS} / \mathrm{A}$ & $\mathrm{PD} / \mathrm{A}$ \\
\hline Birth & 0.319 & 0.132 & 0.309 & 0.133 & 0.372 & 0.070 & 0.367 & 0.081 & 0.271 & 0.420 & 0.266 & 0.456 \\
\hline 4 & 0.478 & 0.309 & 0.465 & 0.324 & 0.529 & 0.180 & 0.519 & 0.199 & 0.433 & 0.536 & 0.418 & 0.562 \\
\hline 8 & 0.642 & 0.568 & 0.629 & 0.600 & 0.681 & 0.390 & 0.667 & 0.414 & 0.611 & 0.648 & 0.588 & 0.662 \\
\hline 12 & 0.779 & 0.795 & 0.767 & 0.825 & 0.802 & 0.651 & 0.788 & 0.667 & 0.763 & 0.746 & 0.739 & 0.749 \\
\hline 16 & 0.873 & 0.920 & 0.865 & 0.938 & 0.885 & 0.845 & 0.874 & 0.851 & 0.869 & 0.825 & 0.849 & 0.819 \\
\hline 20 & 0.931 & 0.972 & 0.926 & 0.981 & 0.936 & 0.942 & 0.928 & 0.943 & 0.932 & 0.885 & 0.918 & 0.871 \\
\hline 24 & 0.964 & 0.991 & 0.961 & 0.996 & 0.965 & 0.980 & 0.960 & 0.980 & 0.966 & 0.926 & 0.957 & 0.909 \\
\hline 28 & 0.981 & 0.998 & 0.979 & 0.999 & 0.981 & 0.994 & 0.978 & 0.994 & 0.983 & 0.955 & 0.978 & 0.936 \\
\hline 32 & 0.990 & 0.999 & 0.989 & 0.999 & 0.990 & 0.999 & 0.988 & 0.999 & 0.992 & 0.974 & 0.989 & 0.954 \\
\hline
\end{tabular}

$C S$ is centroid size, $P D$ is Procrustes distance, and $A$ is the corresponding asymptotic value for shape or size.

lengthen, relative to the basicranium, and the sagittal crest takes shape, between the onset of deciduous tooth replacement and the completion of adult dentition eruption. For the mandible, there is an elongation and deepening of the anteriormost part of the horizontal mandible body between birth and weaning, whereas there is an elongation and deepening of the posterior parts of the body of the mandible and ramus (anterior to the condyloid process) between weaning and the onset of deciduous tooth replacement. These age-specific patterns are distinctive enough to make ontogenetic trajectories during successive life-history stages significantly different from one another.
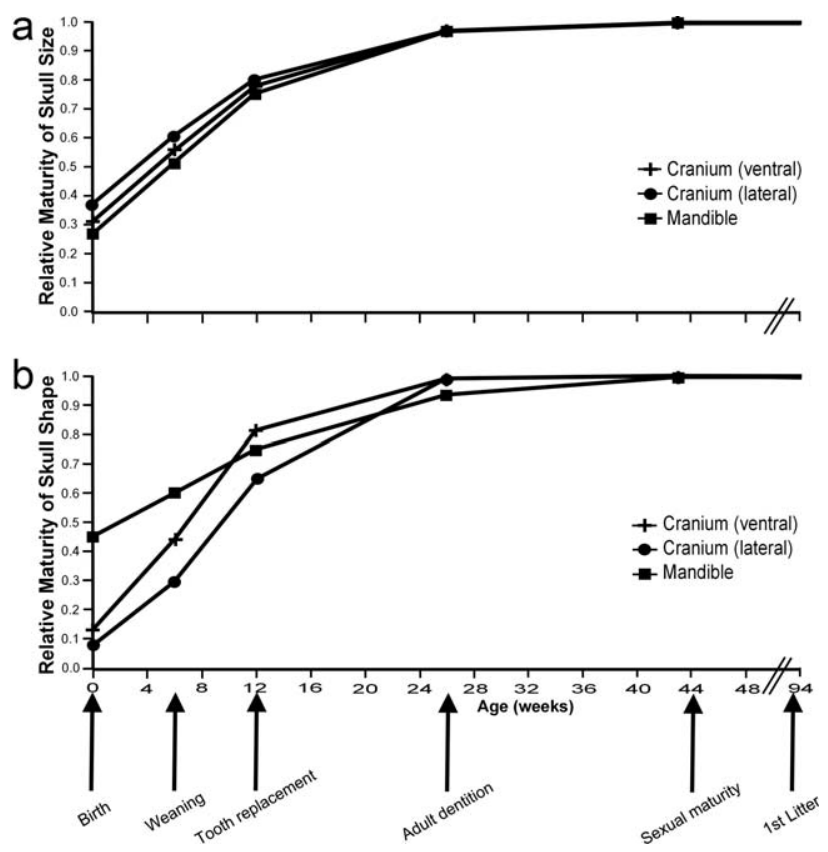

Fig. 6. Timeline illustrating the relative maturity in size (a) and shape (b) for the ventral and lateral views of the cranium and the mandible for coyotes in relation to major life history events. There is no significant difference between males and females in rate of maturation of skull size or skull shape.
The cranium and the mandible are synchronous in their growth, keeping pace with one another as they enlarge, and reaching adult size at the same life-history stage. The cranium itself is also synchronous with respect to growth and development; i.e., cranial size and shape show similar temporal patterns and reach adult levels at the same lifehistory stage. In contrast, whereas mandibular growth keeps pace with cranial growth, the developmental patterns evident in mandibular and cranial shape exhibit striking differences. The mandible is relatively mature in shape at birth, but despite this early maturity, it develops more slowly and attains adult shape later than the cranium (Fig. 7). Any mismatch between the growth and maturation of different parts belonging to a single functional complex can be disruptive unless function itself is also changing. When function is changing, however, constancy of the relationships between parts would not be expected. The functional relationships between cranium and mandible (as well as among regions within each part) do change over postnatal mammalian ontogeny. An

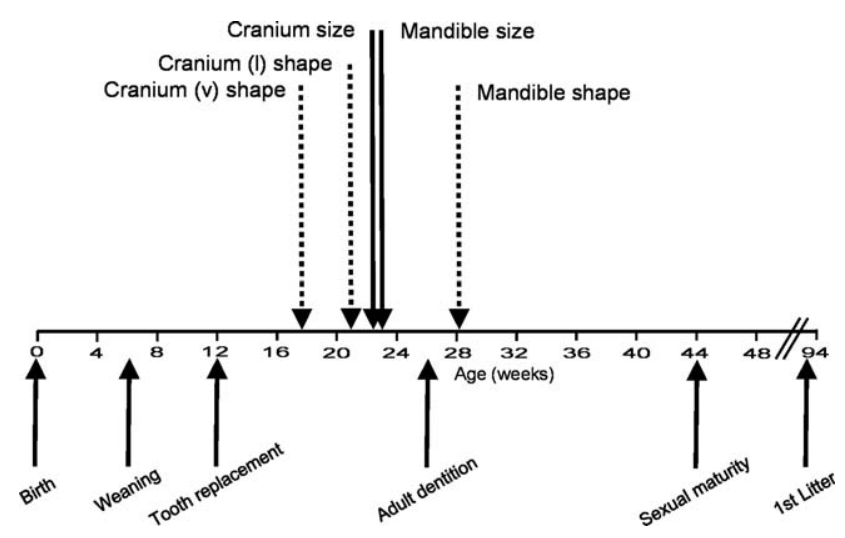

Fig. 7. Timeline illustrating the age at maturation for coyote skull morphology in relation to major life history events. Male and female skull maturation occurs within the same week for each morphological measure; the latest maturation age is indicated for each measure by a downward-pointing arrow. 
obvious example is that suckling and mastication make different demands with respect to occlusion between upper and lower teeth. We might generally expect changes in the relationships among parts unless the demands of adult function are satisfied by the infant morphology. It is, therefore, not surprising that the coyote cranium and mandible each display the complex ontogeny described above, or that the mandible and cranium are asynchronous in development if not in growth.

Adult shape of the coyote feeding apparatus is attained long after the transition to solid food at six weeks of age: cranial shape does not mature for another 11-14 weeks, and mandibular shape, for another 22 weeks. At weaning, cranial shape is as little as $30 \%$ mature, whereas the mandible is already $61 \%$ mature, having been more mature at birth. Thus, juvenile coyotes are far from mature at weaning, so we would expect that their feeding performance at weaning would be poor relative to that of adults. Further, the ongoing maturation of the skull parts suggests that adult function is not achieved by the morphology characteristic of the postweaning stage. Synchrony of cranial and mandibular development may be unnecessary except to the extent that it affects growth and orientation of the masticatory muscles. Bone growth plays a pivotal role in orienting muscles and their action lines, in that regional bone growth differentially stretches the periosteum, with muscles being carried along with it via their periosteal attachments (Grimm and Katele, 1979; Carlson, 1983; Frankenhuis-van den Heuvel et al., 1992). Additionally, bones must grow to accommodate enlarging muscles, so we might anticipate synchrony in regions where masticatory muscles originate and insert, such as the sagittal crest (visible only in lateral view) and mandible. Indeed, our results show that association between mandibular development and sagittal crest; mandibular development in the subadult stage is marked by localized changes in condylar and coronoid shape and these changes are concurrent with localized cranial changes, particularly in the sagittal crest, that continue through adulthood. The influence of developing secondary and primary dentition on the synchrony of cranial and mandibular shape development remains unexplored, but tooth development and occlusion might well affect the synchrony of cranial and mandibular development.

It is not presently known whether the asynchrony shown here in coyote cranial and mandibular shape development reflects a more generalized mammalian pattern because only one other study, on the spotted hyena, Crocuta crocuta (Tanner et al., 2010), has concurrently examined ontogenetic patterns of cranial and mandibular shape change in relation to life history. Hyenas, unlike coyotes, are capable as adults of cracking open large bones using craniodental adaptations for

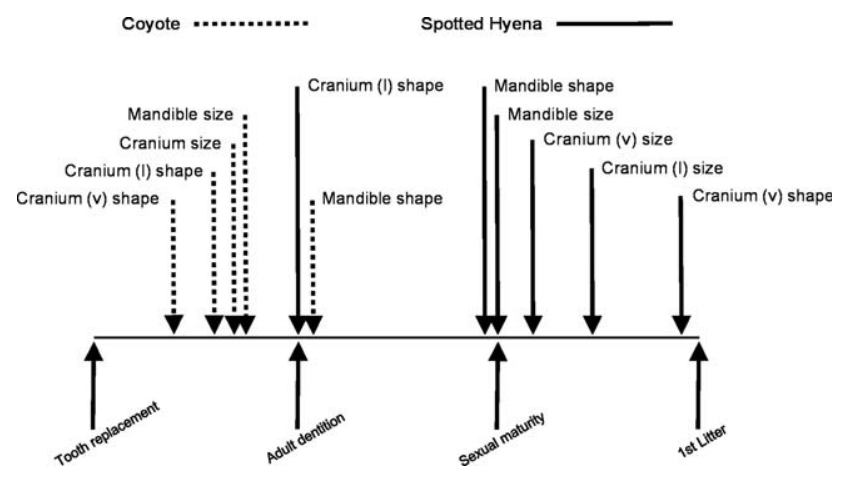

Fig. 8. Comparison of maturation timing of cranium (ventral and lateral views) and mandible between coyotes and spotted hyenas in relation to major life history events. Maturation for coyote (this study) is indicated with a dashed line, and for spotted hyenas (Tanner et al., 2010) with a solid line.

durophagy that include a vaulted forehead, a large sagittal crest, massive zygomatic arches and robust premolars with crack-resistant enamel. Another distinction between hyenas and coyotes may be related to those morphological demands of durophagy: the hyena's life history is notable for its protracted period of maternal dependence even in relation to other large carnivores (Watts et al., 2009). Skull ontogeny in the spotted hyena, like that in coyotes, demonstrates relative synchrony in cranial and mandibular growth but asynchrony in cranial and mandibular shape development, cranial size and shape maturation, and mandibular size and shape maturation (Tanner et al., 2010). What differs strikingly between coyotes and hyenas is both the sequence of adult size and shape maturation events and their timing within the life history (Fig. 8.). In the coyote, mandibular shape matures after cranial shape, and mandibular shape is the last skull measure to mature. By contrast, in the spotted hyena, cranial shape maturation is dramatically delayed, occurring long after mandibular shape maturation. In addition, all coyote skull maturation is completed before or shortly after the eruption of the adult dentition and long before reproductive maturity, but in the spotted hyena, skull maturation (except for cranial shape in the lateral view) occurs at or after reproductive maturity. Like the coyote skull, the spotted hyena skull matures long after weaning, and despite a late age-at-weaning in spotted hyenas (compared to other carnivores), the skull of a just-weaned spotted hyena is still notably immature (ventral, $73.5 \%$ mature; lateral, 90.3\%; mandible, $83.5 \%$, Tanner, unpublished data). Delayed skull maturation in the spotted hyena, especially late cranial maturation and delayed feeding performance maxima, may be explained as costs of the adult ability to crack open large bones. Indeed, the dominant feature of postweaning shape change in a spotted hyena skull is the development of the bony areas 
of muscle insertion: zygomatic arches expand and the sagittal and nuchal crests develop (Tanner et al., 2010). For coyotes and other mammalian carnivores lacking such specialized adult function, we might thus expect a more modest delay in skull maturation and achievement of feeding performance maxima than is seen in spotted hyenas. We have demonstrated the former here; future work is needed to determine whether a comparable delay in maturation also exists regarding achievement of feeding performance maxima and whether maturation schedules influence dietary choices.

Overall, comparison of ontogenetic patterns in coyotes and spotted hyenas reveals that both species share a synchronous pattern of maturation in growth between cranium and mandible, but temporally mismatched patterns of maturation in shape between cranium and mandible. That morphological development does not predict lifehistory events in these two carnivores distinguishes them from the two rodents studied to date; in those two rodents, one precocial, the cotton rat (Sigmodon fulviventer), and the other altricial, the house mouse (Mus musculus domesticus), cranial shape maturity predicted life-history scheduling (Zelditch et al., 2003). In contrast, coyote skull maturity occurs well before sexual maturity, and spotted hyena skull maturity occurs well after.

By looking at growth and development in the cranium and mandible concurrently, examining the relationship between their maturation patterns, and placing both within the context of life history, we can identify a synchronous pattern of maturation in growth across parts as well as a temporally mismatched pattern of shape maturation. It is likely that these patterns are complicated by the interaction between localized features in one part of the skull with those of another (such as the cranial origins and mandibular insertions of masticatory muscles). Clearly, additional studies on carnivores are needed to provide a richer context for interpreting the causes, consequences and functional bases for differences between cranial and mandibular ontogenetic patterns. Of particular importance for understanding the links between morphology, feeding performance, and life history is the protracted period of cranial development in carnivores, which makes juveniles handicapped relative to adults for a significant portion of their life history. Our findings demonstrate that an adult's functional demands cannot be satisfied by the morphology characterizing earlier life-history stages, and this has significant consequences for life-history evolution whenever juveniles must compete with adults.

\section{ACKNOWLEDGMENTS}

The authors are grateful to Doris Zemlicka, Jeff Schultz, Stacey Brummer, Patrick Darrow, and the entire staff at the NWRC Logan Field Station for their work in collecting the specimens used here, and for their cooperation and support. The authors are also indebted to Don Swiderski, Laura Abraczinskas, Paula Hildebrandt, Katherine Leonard, and Andrea Beaudet for their help on this project.

\section{LITERATURE CITED}

Alberch P, Gould SJ, Oster GF, Wake DB. 1979. Size and shape in ontogeny and phylogeny. Paleobiology 5:296-317.

Andelt WF, Kie JG, Knowlton FF, Cardwell K. 1987. Variation in coyote diets associated with season and successional changes in vegetation. J Wildl Manag 51:273-277.

Andresen PR, Bookstein FL, Conradsen K, Ersboll B, Marsh J, Kreiborg S. 2000. Surface-bounded growth modeling applied to human mandibles. IEE Trans Med Imaging 19:1053-1063.

Arjo WM, Pletscher DH, Ream RR. 2002. Dietary overlap between wolves and coyotes in northwestern Montana. J Mammal 83:754-766.

Bekoff M. 1977. Canis latrans. Mammal Species 79:1-9.

Bekoff M. 2001. Behavioral development in coyotes and eastern coyotes. In: Bekoff M, editor. Coyotes: Biology, Behavior, and Management. Caldwell, NJ: The Blackburn Press. pp 97-126.

Bekoff M, Gese EM. 2003. Coyote (Canis latrans). In: Feldhamer GA, Thompson BC, Chapman JA, editors. Wild Mammals of North America: Biology, Management, and Conservation, 2nd ed. Baltimore, Maryland: John Hopkins University Press. pp 467-481.

Bookstein FL. 1991. Morphometric Tools for Landmark Data: Geometry and Biology. Cambridge: Cambridge Unviversity Press.

Bookstein FL, Streissguth AP, Sampson PD, Connor PD, Barr HM. 2002. Corpus callosum shape and neuropsychological deficits in adult males with heavy fetal alcohol exposure. Neuroimage 15:233-251.

Boughner J, Dean M. 2008. Mandibular shape, ontogeny and dental development in bonobos (Pan paniscus) and chimpanzees (Pan troglodytes). Evol Biol 35:296-308.

Bowen WD. 1978. Social organization of the coyote in relation to prey size. Doctor of Philosophy, University of British Columbia. $230 \mathrm{p}$.

Cardini A, O'Higgins P. 2005. Post-natal ontogeny of the mandible and ventral cranium in Marmota species (Rodentia, Sciuridae): Allometry and phylogeny. Zoomorphology 124:189-203.

Cardini A, Tongiorgi P. 2003. Yellow-bellied marmots (Marmota flaviventris) 'in the shape space' (Rodentia, Sciuridae): Sexual dimorphism, growth and allometry of the mandible. Zoomorphology 122:11-23.

Carlson DS. 1983. Growth of the masseter muscle in rhesus monkeys (Macaca mulatta). Am J Phys Anthropol 60:401410.

Christiansen P. 2008. Evolution of skull and mandible shape in cats (Carnivora: Felidae). PLoS ONE 3:e2807.

Clark FW. 1972. Influence of jackrabbit density on coyote population change. J Wildl Manag 36:343-356.

Frankenhuis-van den Heuvel THM, Maltha JC, Kuijpers-Jagtman AM, van't Hof MA. 1992. A longitudinal radiographic study of the periosteal migration along the growing rabbit mandible. J Dent Res 71:398-402.

Gaillard J-M, Pontier D, Allaine D, Loison A, Herve J-C, Heizmann A. 1997. Variation in growth form and precocity at birth in eutherian mammals. Proc R Soc Lond B 264:859868.

Gese EM, Ruff RL, Crabtree RL. 1996. Intrinsic and extrinsic factors influencing coyote predation of small animals in Yellowstone National Park. Can J Zool 74:784-797.

Gould SJ. 1977. Ontogeny and Phylogeny. Cambridge, MA: Harvard University Press. 
Grimm AF, Katele KV. 1979. "Silver dust"-A tool to study growth interrelationships between bone, periosteum and muscle. Anat Rec 194:539-546.

Harrison DJ, Gilbert JR. 1985. Denning ecology and movements of coyotes in maine during pup rearing. J Mammal 66:712-719.

Harrison DJ, Harrison JA, Odonoghue M. 1991. Predispersal movements of coyote (Canis latrans) pups in eastern Maine. J Mammal 72:756-763.

Hawthorne VM. 1970. Movements and food habits of coyotes in the Sagehen Creek Basin and Vicinity. Master of Science, Reno, NV, University of Nevada. 78 p.

Hernandez L, Parmenter RR, Dewitt JW, Lightfoot DC, Laundre JW. 2002. Coyote diets in the Chihuahuan Desert, more evidence for optimal foraging. J Arid Environ 51:613624.

Herrel A, Gibb AC. 2006. Ontogeny of performance in vertebrates. Physiol Biochem Zool 79:1-6.

Hidalgo-Mihart MG, Cantu-Salazar L, Lopez-Gonzalez CA Martinez-Meyer E, Gonzalez-Romero A. 2001. Coyote (Canis latrans) food habits in a tropical deciduous forest of western Mexico. Am Midland Nat 146:210-216.

Johnson MK. 1978. Food habits of coyotes in southcentral Idaho. Doctor of Philosophy, Fort Collins, CO, Colorado State University.77 p.

Kieser JA, Groeneveld HT. 1992. Comparative morphology of the mandibulodental complex in wild and domestic canids. J Anat 180:419-424.

Marquez E. 2007. Sage. Version 1.03. Ann Arbor, MI: University of Michigan Museum of Zoology.

McKinney ML, McNamara KJ. 1991. Heterochrony: The Evolution of Ontogeny. New York: Plenum Press.

Monteiro LR, Lessa LG, Abe AS. 1999. Ontogenetic variation in skull shape of Thrichomys apereoides (Rodentia: Echimyidae). J Mammal 80:102-111.

Moore WJ. 1981. The Mammalian Skull. Cambridge: Cambridge University Press.

Rohlf FJ. 2005. tpsDig 2.10. Stony Brook, NY: SUNY.
Rohlf FJ. 2007. tpsRegr 1.34. Stony Brook, NY: SUNY.

Rohlf FJ, Slice DE. 1990. Extensions of the procrustes method for the optimal superimposition of landmarks. Syst Zool 39:40-59.

Sampson PD, Bookstein FL, Sheehan H, Bolson EL. 1996. Eigenshape analysis of left ventricular outlines from contrast ventriculograms. In: Marcus LF, Corti M, Loy A, Naylor GJP, Slice DE, editors. Advances in Morphometrics. New York: Nato ASI Series, Series A: Life Science. pp 131-152.

Sheets DH. 2003. IMP-Integrated Morphometrics Package. Buffalo, NY: Department of Physics, Canisius College.

Sheets DH. 2009. CoordGen6h. Buffalo, NY: Department of Physics, Canisius College.

Snow CJ. 1967. Some observations on the behavioral and morphological development of coyote pups. Am Zool 7:353-355.

Tanner JB, Zelditch ML, Lundrigan BL, Holekamp KE. 2010. Ontogenetic change in skull morphology and mechanical advantage in the spotted hyena (Crocuta crocuta). J Morphol 271:353-365.

Wainwright PC, Reilly SM,editors. 1994. Ecological Morphology. Chicago, IL: University of Chicago Press.

Watts HE, Tanner JB, Lundrigan BL, Holekamp KE. 2009. Post-weaning maternal effects and the evolution of female dominance in the spotted hyena. Proc R Soc B 276:22912298.

Wayne RK. 1986. Developmental constraints on limb growth in domestic and some wild canids. J Zool 210:381-399.

Young JK, Andelt WF, Terletzky PA, Shivik JA. 2006. A comparison of coyote ecology after 25 years: 1978 versus 2003. Canad J Zool-Revue Canad De Zool 84:573-582.

Zelditch ML, Lundrigan BL, Sheets HD, Garland J,T. 2003. Do precocial mammals develop at a faster rate? A comparison of rates of skull development in Sigmodon fulviventer and Mus musculus domesticus. J Evol Biol 16:708-720.

Zelditch ML, Lundrigan BL, Garland T. 2004. Developmental regulation of skull morphology. I. Ontogenetic dynamics of variance. Evol Dev 6:194-206. 